Article

\title{
Incorporating a Canopy Parameterization within a Coupled Fire-Atmosphere Model to Improve a Smoke Simulation for a Prescribed Burn
}

\author{
Derek V. Mallia ${ }^{1, *}$, Adam K. Kochanski ${ }^{1,2}$, Shawn P. Urbanski ${ }^{3}$, Jan Mandel ${ }^{4}(\mathbb{D}$, \\ Angel Farguell ${ }^{4}(\mathbb{B})$ and Steven K. Krueger ${ }^{1}$ \\ 1 Department of Atmospheric Sciences, University of Utah, Salt Lake City, UT 84112, USA; \\ adam.kochanski@utah.edu (A.K.K.); Steve.Krueger@utah.edu (S.K.K.) \\ 2 Department of Meteorology and Climate Science, San José State University, San Jose, CA 95192, USA \\ 3 Missoula Fire Science Laboratory, U.S. Forest Service, Missoula, MT 59808, USA; \\ shawn.p.urbanski@usda.gov \\ 4 Department of Mathematical and Statistical Sciences, University of Colorado Denver, \\ Denver, CO 80204, USA; Jan.Mandel@ucdenver.edu (J.M.); ANGEL.FARGUELLCAUS@ucdenver.edu (A.F.) \\ * Correspondence: Derek.Mallia@utah.edu
}

Received: 18 July 2020; Accepted: 5 August 2020; Published: 7 August 2020

\begin{abstract}
Forecasting fire growth, plume rise and smoke impacts on air quality remains a challenging task. Wildland fires dynamically interact with the atmosphere, which can impact fire behavior, plume rises, and smoke dispersion. For understory fires, the fire propagation is driven by winds attenuated by the forest canopy. However, most numerical weather prediction models providing meteorological forcing for fire models are unable to resolve canopy winds. In this study, an improved canopy model parameterization was implemented within a coupled fire-atmosphere model (WRF-SFIRE) to simulate a prescribed burn within a forested plot. Simulations with and without a canopy wind model were generated to determine the sensitivity of fire growth, plume rise, and smoke dispersion to canopy effects on near-surface wind flow. Results presented here found strong linkages between the simulated fire rate of spread, heat release and smoke plume evolution. The standard WRF-SFIRE configuration, which uses a logarithmic interpolation to estimate sub-canopy winds, overestimated wind speeds (by a factor 2), fire growth rates and plume rise heights. WRF-SFIRE simulations that implemented a canopy model based on a non-dimensional wind profile, saw significant improvements in sub-canopy winds, fire growth rates and smoke dispersion when evaluated with observations.
\end{abstract}

Keywords: wildland fire; smoke modeling; coupled-fire atmosphere model; canopy winds

\section{Introduction}

Wildland fires across North America are projected to increase in frequency and in size through the 21st century as a result of climate change [1-3]. An increase in wildfire activity is already being observed across the western U.S. over the past several decades as a result of a longer wildfire season and previous land use and fire management practices [4-6]. Air quality across the western U.S. has also started to deteriorate, especially across the Pacific Northwest and Northern Rockies as a result of increased wildfire activity and smoke [7]. Air quality across these regions is expected to deteriorate through the foreseeable future [8]. As wildfires continue to increase in frequency and intensity, numerical models are needed that can assist with forecasting fire evolution and smoke impacts on regional air quality.

A number of models currently exist that forecast wildland fires and/or smoke. One-way coupled modeling frameworks such as BlueSky [9] and the High-Resolution Rapid Refresh model (HRRR) with smoke (HRRR-smoke; Ahmadov et al., [10]) estimate smoke emissions and parameterize fire 
plume heights. Smoke is then dispersed using a chemical transport model such as CMAQ or treated as a passive scalar within an atmospheric model (e.g., HRRR). Coupled fire-atmosphere models such as WRF-SFIRE [11] render two-way interactions between the atmosphere and fire. In these models, heat and moisture fluxes at the fireline are fed back into the atmospheric core, altering local air temperature, humidity, and winds, which are responsible for driving fire behavior, and smoke emissions and dispersion [12,13]. Coupled fire-atmosphere models can also explicitly resolve pyroconvection and therefore do not rely on external plume rise parameterizations.

Coupled fire-atmosphere models often use semi-empirical fire spread formulas to simulate fire growth. Fire spread models, such as the Rothermel model [14] parameterize fire growth based on a number of variables such as wind speed, slope, and fuel characteristics. Fire growth rates are strongly dependent on the midflame height wind, which drives fire propagation. Typically, these winds are computed from the wind speed at a reference height of $6.1 \mathrm{~m}(20 \mathrm{ft})$ and then scaled to the fire's mid-flame height using a dimensionless wind adjustment factor (WAF). Values for the WAF vary between 0 and $1[15,16]$ and depend on the fuel type and canopy characteristics [17]. This method is widely used for U.S. fire behavior prediction systems as it is (1) numerically efficient and (2) does a reasonable job generalizing the vegetation impact on winds across a large and diverse landscape [17].

While the WAF is an efficient and robust way to estimate winds at the fire mid-flame height, it makes compromises in regard to the physical realism of wind profiles within the forest canopy $[18,19]$. For example, winds within the forest canopy are assumed to be uniform, thus the WAF method neglects the impacts of forest canopy structure on the canopy wind profile [20]. The WAF method also disregards the influences of foliage density, which can have ramifications for estimating near-surface winds in landscapes with partial canopy cover. Idealized numerical simulations carried out by Kiefer et al. [21] showed that within canopy winds, kinematics, and temperature can be sensitive to the vertical canopy structure. An improved canopy wind model was recently developed by Massman et al. [19], which can characterize a canopy wind profile based on the canopy structure and foliage density for a given tree type. Results from Massman et al. [19] found that their method was able to reproduce wind profiles for a variety of different canopy types.

Since simulated fire spread rates are strongly dependent on within-canopy winds, fire behavior and coupled fire-atmosphere models are sensitive to how the canopy wind profile is prescribed. Errors in the derived midflame winds can result in misrepresented fire growth that can affect the accuracy of wildfire smoke simulations [12]. Typical numerical weather prediction (NWP) models do not resolve winds within the canopy, as the top of the first model layer is generally located above the canopy top. While NWP models try to account for the overall canopy drag through parameterizations, these models are unable to render the wind flow within the forest canopy. This can be problematic for coupled fire-atmosphere models as canopy-affected winds are critical for accurately simulating the fire rate of spread and fuel consumption. Furthermore, recent work carried out by Charney et al. [22] indicated that smoke dispersion and fire plume heights can be strongly dependent on how near-surface winds are used to estimate fire growth, especially within forest canopies.

For this study, we quantified the impacts of within-canopy wind profiles on midflame winds, fire growth, plume rises, and smoke dispersion. In addition, we sought to improve the capabilities of WRF-SFIRE in representing plume evolution by implementing a canopy wind parameterization. In an effort to quantify the impacts of canopy winds on forecasted fire growth and smoke dispersion, we modeled a prescribed burn within a forest during the Prescribed Fire Combustion and Atmospheric Dynamics Research Experiment (RxCADRE). RxCADRE represents one of the most comprehensive efforts to characterize fuels and fuel consumption while simultaneously monitoring a fire, its surrounding micrometeorology, and downwind smoke dispersion [23-26]. Fire simulations and smoke dispersion for RxCADRE were generated using the Weather and Research and Forecast model coupled with a fire spread model (WRF-SFIRE) [11,13].

In the following sections, we will briefly describe the experimental setup for RxCADRE, and the observations used to initialize and evaluate the modeling framework presented here (Section 2.1). 
Section 2.2 will describe the model setup and three configurations used to simulate a prescribed burn during RxCADRE. This section will then be followed up by the results, which analyzed the simulated fire growth and smoke dispersion for 3 different WRF-SFIRE configurations. Finally, the results of this study were synthesized in the conclusion (Section 4).

\section{Methods}

\subsection{RxCADRE Description}

Several prescribed burns were carried out at Eglin Air Force Base, FL, between 31 October and 12 November 2012, as part of the RxCADRE field campaign. The primary goal of RxCADRE was to develop a comprehensive dataset that could be used to evaluate fine-scale fire behavior and coupled fire-atmosphere models. This experiment consisted of six smaller $100 \times 200 \mathrm{~m}$ burn blocks and three operational scale $\left(\sim 1 \mathrm{~km}^{2}\right)$ burn plots. One of the larger prescribed burns (L2F) took place within a $1.51 \mathrm{~km}^{2}$ forested plot between 18:04 and 20:59 UTC on 11 November 2012 (Figure 1). The L2F burn plot consisted of a mixture of long leaf pine with deciduous oak trees with surface fuels being made up of pine and oak litter, and fine dead woody debris [24,25]. Since the L2F plot mostly consisted of trees, it presented as an ideal opportunity to test canopy wind parameterizations.

The L2F burn was ignited along 3 lines, which transected the L2F plot from the northeast to southwest. The L2F burn was instrumented with a number of wind anemometers located throughout the plot along with a tall tower that was situated on the periphery of the burn unit [23]. In addition, an aircraft equipped with a Wildfire Airborne Sensor Program (WASP) sensor was used to measure fire radiative power $[27,28]$, while another airborne measurement platform collected smoke measurements within the L2F smoke plume [25].

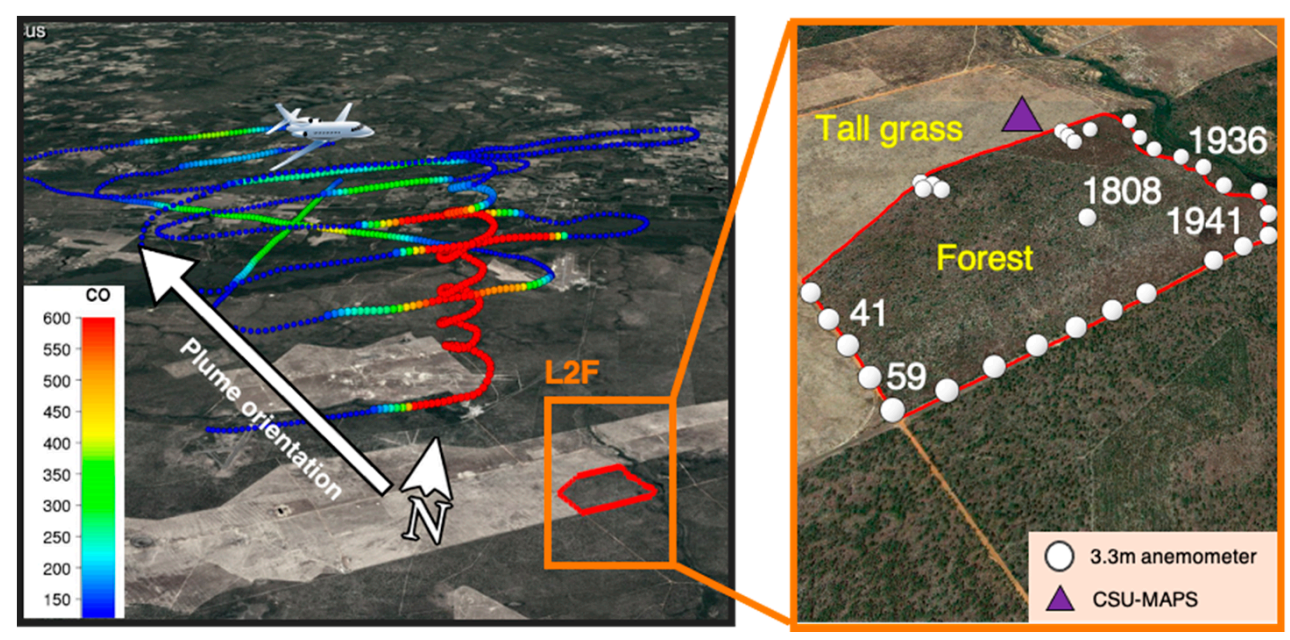

Figure 1. The panel on the left shows a 3-dimensional diagram of aircraft-measured CO enhancements (ppb) during the L2F prescribed burn. The L2F burn plot is outlined in red. The panel on the right is zoomed in on L2F burn plot and shows the location of the 3.3-m anemometers and the CSU-MAPS tall tower.

During the L2F burn, prevailing winds were out of the southeast due to the presence of a large anticyclone located over North and South Carolina. Ambient air temperatures varied between 20 and $25{ }^{\circ} \mathrm{C}$, with relative humidity values ranging between $45-65 \%$ during the burn. Two radiosondes launched at 15:00 and 21:00 UTC indicated the presence of two stable layers located at 600 and $1500 \mathrm{mASL}$. By 21:00 UTC, the lowest stable layer had eroded as a result of daytime convective mixing. The second stable layer located at $1500 \mathrm{mASL}$ separated the marine layer from the free troposphere and was persistent throughout the L2F prescribed burn [29]. 


\subsubsection{Wind Measurements}

The L2F burn plot was instrumented with 36 Onset Computer Corporation cup-and-vane anemometers with a measurement height of $3.3 \mathrm{mAGL}$ and a sampling frequency of $3 \mathrm{~s}$ (Figure 1). The California State University-Mobile Atmospheric Profiling System (CSU-MAPS) $32 \mathrm{~m}$ tower was located on the periphery of the L2F burn plot (Figure 1). This tower was equipped with Vaisala Thermistor-hygristor sensors, Windsonic 2D anemometers, and RM Young 81,000 3D sonic anemometers at 7 and 31 mAGL [23].

\subsubsection{Infrared Measurements}

Airborne fire radiative power (FRP) measurements were collected using a longwave infrared sensor (8 to $9.2 \mu \mathrm{m}$ nominal bandpass) placed on a fixed-wing aircraft [24]. Airborne FRP measurements were used to estimate the intensity of the fire and map the fire perimeter every 200-300 s. Infrared measurements were retrieved starting from the ignition time at 18:04 UTC through the end of the burn at 20:59 UTC. Infrared fire perimeters were used to initialize the starting fire location within WRF-SFIRE, which is discussed in further detail within Section 2.2.

\subsubsection{Smoke Measurements}

Smoke measurements during the L2F prescribed burn were collected using a Picarro Cavity Ring-Down Spectroscopy (CRDS) gas analyzer equipped on a twin-engine Cessna 337. Air from the smoke plume and surrounding atmosphere was filtered through a stainless-steel inlet with a diameter of 1.27- $\mathrm{cm}$ located near the pilot window. The CRDS gas analyzer retrieved measurements for $\mathrm{CO}_{2}$, $\mathrm{CO}, \mathrm{CH}_{4}$, and water vapor every $2 \mathrm{~s}$ between 17:42 and 20:59 UTC (Figures 1 and 2) [25,30]. During the flight, the aircraft made a number of horizontal transects and vertical ascents/descents in an effort to characterize the smoke plume from the L2F prescribed burn. The twin-engine Cessna 337 made these transects between 4 and 25-km downwind of the L2F plot.
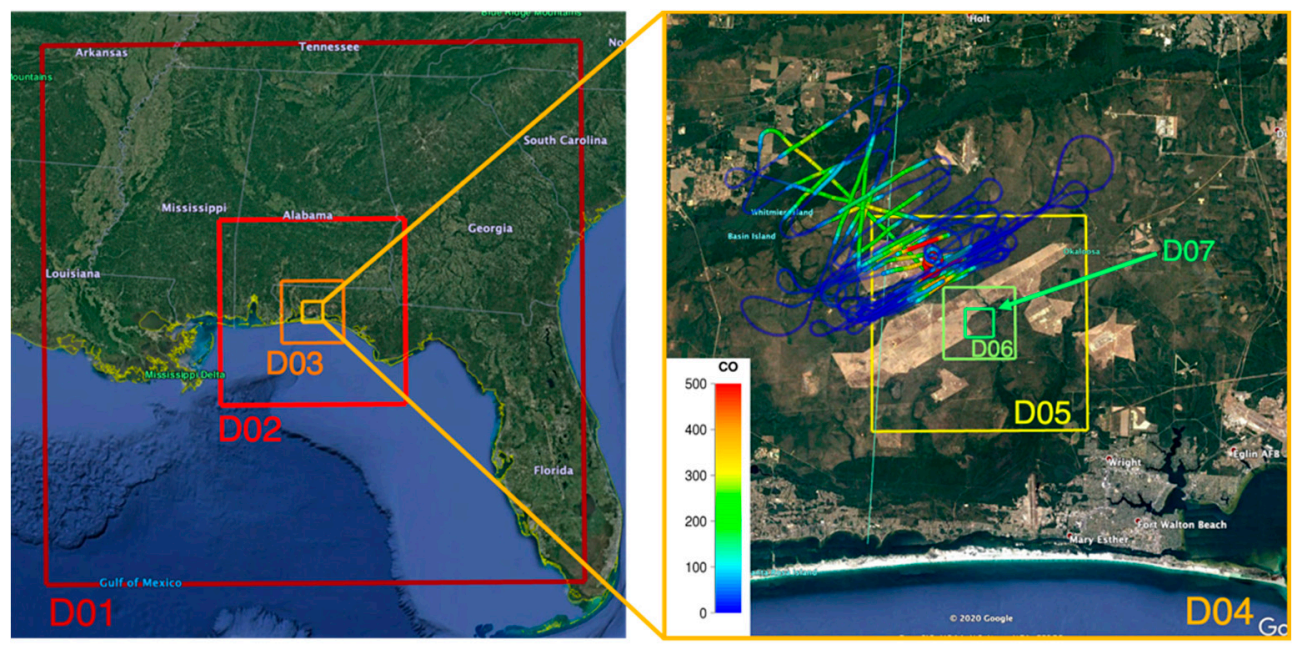

Figure 2. WRF-SFIRE domain configuration centered over the L2F burn plot. Colored dots represent downwind $\mathrm{CO}$ enhancements (ppb).

\subsection{Model Configuration}

\subsubsection{Atmospheric Model Setup}

Simulations for the L2F prescribed burn were generated using a coupled fire-atmosphere model (WRF-SFIRE), which can simultaneously model the atmosphere, fire growth, fire emissions, fuel conditions, and smoke dispersion. The WRF component of the WRF-SFIRE modeling framework is responsible for simulating larger-scale atmospheric motions and parameterizing sub-grid-scale 
processes such as cloud microphysics, land-surface interactions, and radiation exchanges [31]. This modeling framework uses two-way coupling, which allows WRF-SFIRE to account for fire-atmosphere interactions such as the fire plume rise, changes in the dead fuel moisture, and modifications in local winds near the advancing fire front.

The WRF-SFIRE simulation used a 2-way nested domain configuration with 7 progressively smaller domains that were centered on the L2F burn plot (Figure 2). This setup allowed WRF to gradually downscale coarser-scale meteorological boundary conditions to the resolution needed to simulate meteorology across the L2F burn plot. In addition, two-way nesting was employed to allow smoke generated within the innermost domain to feed back into the progressively coarser model domains, where most of the smoke observations were made (Figure 2). The innermost domain (d07), had a grid spacing of $16.5 \mathrm{~m}$ and encompassed the L2F burn plot. Since the L2F burn plot had dimensions of $\sim 1000 \times 1680 \mathrm{~m}$, it was important to select an atmospheric grid spacing that could resolve the spatial variability of the fire-affected wind field. The WRF domains used a grid spacing ratio of 3:1, where the outermost domain (d01) had a grid spacing of $12 \mathrm{~km}$. The remaining WRF domains (d02-06) had grid spacings of $4,1.333,0.4444,0.1481$, and $0.0493 \mathrm{~km}$. The Climate Forecast System Reanalysis [32] was used to initialize meteorology within our WRF-SFIRE simulations.

The WRF-SFIRE simulations in this study were initialized $\sim 6 \mathrm{~h}$ prior (12:00 UTC) to the ignition of the prescribed burn to allow the model to spin-up micro- and meso-scale circulations across our study domain. Model simulations were terminated at the conclusion of the L2F prescribed burn at 21:00 UTC. Each WRF-SFIRE domain had 41 vertical levels, with 17 levels located within the first $1000 \mathrm{mASL}$. The first model layer at was located at $2.7 \mathrm{~m}$ above the ground, while the next 7 models were located at $8.1,16.3,27.2,38,50.2,63.8$, and $89.5 \mathrm{~m}$, on average. For the simulations carried out here, we used the Yonsei University planetary boundary layer scheme [33], 5-layer thermal diffusion parameterization for land-surface physics, rapid radiative transfer model for longwave and shortwave radiation [34], and the Lin et al. [35] microphysical scheme. The Grell-Devenyi cumulus parametrization [36] was applied to the 3 outermost domains (d01-03), while no cumulus physics were used for the four remaining domains (d04-07). The WRF parameterizations selected here follow the settings chosen within Mallia et al. [29], which was able to successfully model downwind smoke from the L2F prescribed burn.

\subsubsection{Fire Model Setup}

The L2F fire was simulated within d07 of our WRF-SFIRE simulation on a 1:10 refined mesh with $1.65 \mathrm{~m}$ grid spacing. Fire spread rates within WRF-SFIRE were parameterized using the Rothermel model [14]. Winds within WRF were interpolated to the fire reference height $(6.1 \mathrm{~m})$ and then adjusted to the fire mid-flame height using fuel-specific wind adjustment factors [37]. Similarly, fuel characteristics within WRF-SFIRE were based on the 13 Anderson fuel classes. Fuel-specific wind reduction factors from Albini and Baughman [15] were used to convert the $6.1 \mathrm{~m}$ winds to the fire midflame winds. Fuel types within the L2F burn plot were classified as southern rough (fuel category 8 ). The fuel moisture model [38] used within SFIRE is dynamically coupled with WRF and provides fuel moisture estimates that can be used in the computation of fire spread rates. The fuel moisture model was initialized by fuel moisture measurements taken shortly before the L2F prescribed burn [24]. Fuel loading within WRF-SFIRE was adjusted to reflect pre- and post-fuel consumption measurements for the L2F prescribed burn [24]. On average, surface fuel loadings were approximated as $0.963 \mathrm{~kg} \mathrm{~m}^{-2}$ for the L2F burn. Fire emissions and heat fluxes were calculated using the simulated fire progression and the prescribed surface fuel loadings for each actively burning gridcell. Heat fluxes generated from the modeled fire were used to vertically distribute smoke emissions within WRF-SFIRE by explicitly resolving the fire plume rise. Lastly, airborne FRP measurements were used to map the progression of the $\mathrm{L} 2 \mathrm{~F}$ prescribed burn, and to initialize and constrain the initial fire progression while the L2F fire lines were ignited.

Three WRF-SFIRE model configurations were used to simulate the L2F prescribed burn. The first configuration used airborne FRP data to prescribe fire growth throughout the duration of the burn. 
This run was used as a benchmark to determine WRF-SFIRE's ability to accurately simulate smoke dispersion when the fire model is bypassed and the fire growth perfectly matches observations. In this run, the fire growth was constrained using a fire arrival time map derived from infrared observations. Thus, the Rothermel fire spread model was not activated for this configuration. This configuration will be referred to as the constrained model simulation.

The second WRF-SFIRE configuration used the standard WAF approach where adjustment factors were used to estimate winds at the mid-flame height, based on the 6.1 m modeled winds. The WAF is dependent on the burning grid cells fuel classification and is the default configuration used by WRF-SFIRE. Since a canopy model was not used here, WRF winds were logarithmically interpolated to the fire reference height of $6.1 \mathrm{~m}$ and then adjusted to the midflame height using the WAF. Going forward, this implementation will be referred to as the default configuration.

The final WRF-SFIRE configuration replaced the default WAF implementation with the improved canopy wind model described in Massman et al. [19]. This implementation will henceforth be referred to as the improved canopy model (ICM). Here, winds within WRF were first interpolated to the canopy top. Then, winds between the surface and the canopy top were parameterized using a normalized wind profile constructed based on canopy structure and foliage density (Figure 3). Here, we assumed that the canopy structure for the L2F burn plot most closely resembled that of a hardwood forest. Within the ICM, it was assumed that the canopy top was uniform across the plot and located at $22.5 \mathrm{~m}$, with the greatest foliage density being positioned near the top of the forest canopy. Parameterized winds within the canopy were then interpolated to the fire mid-flame height. For this study, the mid-flame height was approximated as the depth of the fuel bed [17]. Fuel depths were prescribed based on a look up table for the 13 Anderson fuel classes [37]. For this study, we assumed the L2F plot had a full, spatially uniform canopy cover.

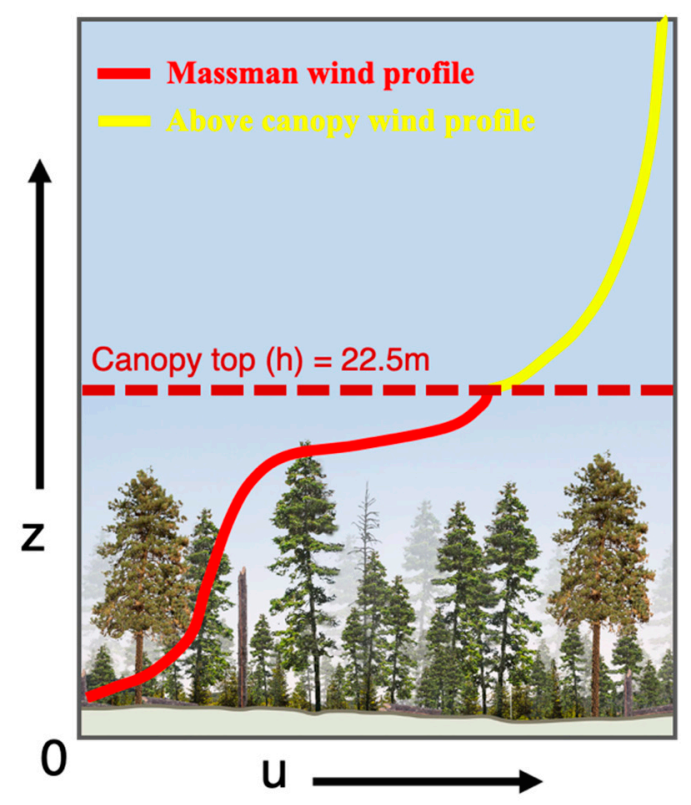

Figure 3. An illustration of the method used to extrapolate above canopy WRF winds to the canopy floor using the ICM parameterization.

\section{Results}

\subsection{L2F Wind Analysis}

Prior to the initiation of the burn at 18:04 UTC, model simulations of wind were compared to wind measurements at the $3.3 \mathrm{~m}$ cup-and-vane anemometers and the CSU-MAPS tall tower. These comparisons were carried out between 17:00-17:59 UTC. Winds measured at the CSU-MAPS 
tall tower $(31 \mathrm{~m})$, which is representative of the ambient wind above the L2F burn plot, varied between 5-8 $\mathrm{m} \mathrm{s}^{-1}$ (Figure 4a). WRF winds, which were interpolated to $31 \mathrm{~m}$ using log interpolation, were slightly overestimated by $0.7 \mathrm{~m} \mathrm{~s}^{-1}$ (relative bias $=+14 \%$ ). In addition, WRF winds also exhibited less variability relative to the measured winds (Figure 4a). Since comparisons at the CSU tower were above the canopy top $(22.5 \mathrm{~m})$, there were no differences between the ICM and default simulated winds.

For comparisons at the $3.3 \mathrm{~m}$ anemometer stations, WRF winds were first interpolated to canopy top using $\log$ interpolation $(22.5 \mathrm{~m})$. Winds at the canopy top height were then scaled down to $3.3 \mathrm{~m}$ using the $\log$ wind profile. Wind errors at the $3.3 \mathrm{~m}$ anemometer stations were much more significant (orange dashed line) relative to the errors at the CSU tall tower at $31 \mathrm{~m}$. The majority of these sites reported large overestimations in wind speeds that ranged between $0.9-2.6 \mathrm{~m} \mathrm{~s}^{-1}$ (relative bias $=+25-200 \%$ ). These errors were more pronounced at sites located within the middle of the L2F burn plots (Figure $4 \mathrm{~d}-\mathrm{f}$ ) than sites located on the western periphery (Figure $4 \mathrm{~b}, \mathrm{c}$ ). The relatively low biases reported at the CSU-MAPS tall tower (Figure 4a) suggest that WRF was able to accurately resolve the ambient wind above the burn plot. From this analysis, it can be hypothesized that overestimated winds near the surface were likely a result of neglecting flow deceleration within the forest canopy.

Simulated near-surface winds were improved when winds were adjusted using the ICM (red dashed line). Here, WRF winds were first interpolated to the canopy top $(22.5 \mathrm{~m})$ using log interpolation, and then scaled to $3.3 \mathrm{~m}$ using the ICM. A number of stations, particularly those located deep within the forested regions of L2F, exhibited smaller wind biases that ranged from $\sim 0.1-0.8 \mathrm{~m} \mathrm{~s}^{-1}$ (Figure $4 \mathrm{~d}-\mathrm{f}$ ). Overall, 32 of 36 sites (not all are shown) had reductions in biases, while the 4 remaining sites saw larger biases when implementing the ICM parameterization. These errors were most pronounced at sites 41 and 59 (Figure $4 \mathrm{~b}, \mathrm{c}$ ), where the ICM implementation resulted in an underestimation of winds (bias $=-1.6$ and $-2.0 \mathrm{~m} \mathrm{~s}^{-1}$ ). As eluded to earlier, these stations were located on the periphery of the L2F burn plot in a less sheltered area since they were adjacent to a grassy field (Figure 1).

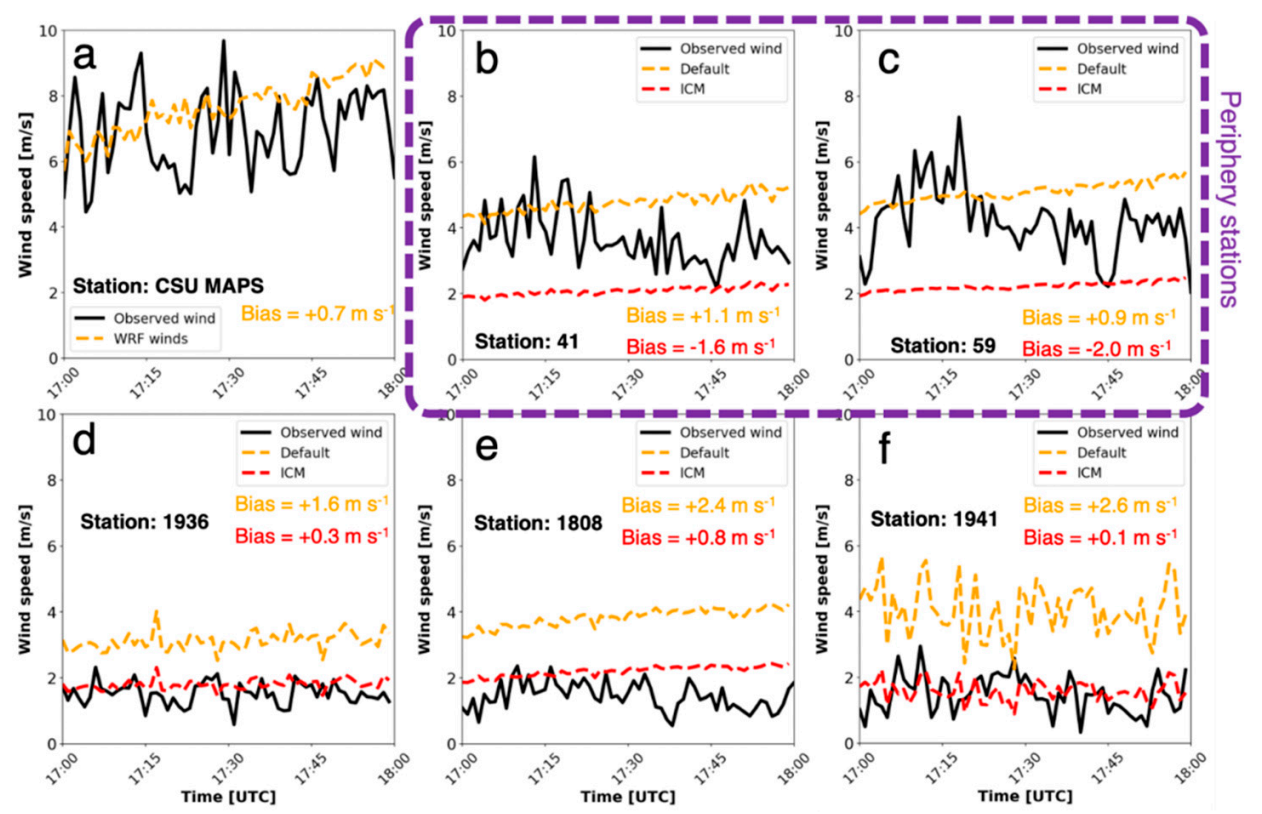

Figure 4. Wind comparisons at six wind measurement sites near or within the L2F burn plot between 17:00-17:59 UTC on 11 November 2012. The black line represents measured wind speeds, while the orange line represents WRF modeled wind winds interpolated to the measurement height location. The red line represents WRF estimated wind speeds that were adjusted by the ICM parameterization. Panel (a) shows wind comparisons at 31-m for the CSU-MAPS tall tower, while panels (b)-(f) are comparisons at the 3-m anemometer stations. 


\subsection{L2F Fire Simulations}

As first described in Section 2.2.2, three WRF-SFIRE simulations were carried out for the L2F experimental burn. The first simulation constrained the L2F fire growth based on IR data, while the second simulation used the standard WAF definition without a canopy model to estimate fire growth rates (default method). The third configuration parameterized the canopy winds using the Massman et al., [19] canopy model (ICM).

The WRF-SFIRE simulation that used the default implementation overestimated the fire growth during the L2F prescribed burn as shown in Figure 5. Starting from the end of the model spin-up up period, this configuration overestimated fire growth rates by a factor of 2 until reaching the edge of the L2F burn plot at 19:15 UTC (burn rate $=6.7$ acres $\mathrm{min}^{-1}$ ). Upon reaching this point, fire growth quickly decelerated as much of the plot was burned. Overpredicted fire spread rates likely stemmed from the absence of canopy representation, which resulted in overestimated winds as seen in Figure 4 . Fire growth rates using the ICM method were improved, and closely resembled fire progression estimated from infrared fire perimeters. Similar to the observations, the fire growth rates within the ICM simulation averaged 3.3 acres $\mathrm{min}^{-1}$. The fire progression in the model also closely resembled that of the observed progression according to infrared observations (not shown). The reduction in fire burn rates can be attributed to the implementation of a canopy model within the ICM simulation, which eliminated overestimates of sub-canopy winds. By 20:00 UTC, burn rates decelerated as the observed and ICM fires approached the edge of the L2F burn plot (Figure 5).

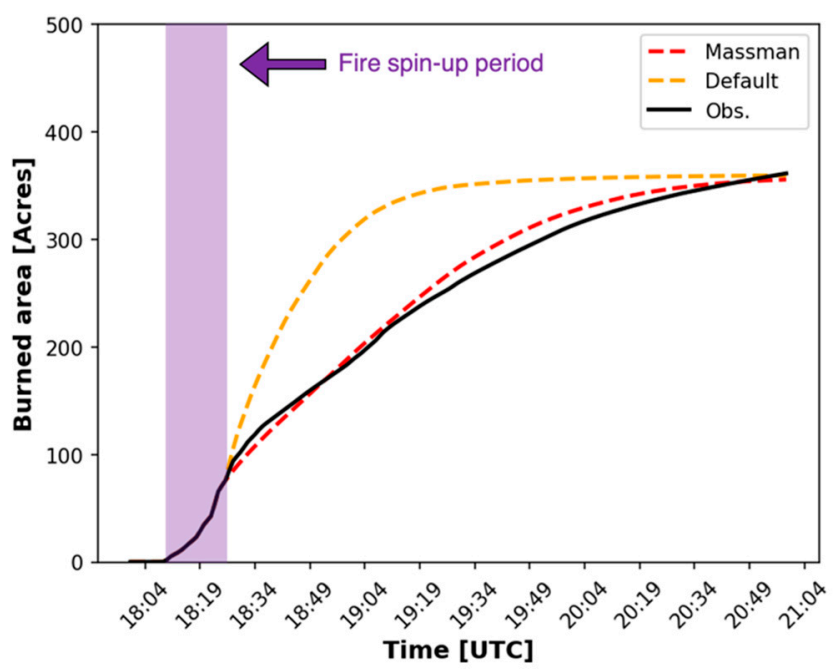

Figure 5. Time series of the fire burned area from infrared observations (black line), WRF-SFIRE simulations using the standard WAF assumption without a canopy wind model (orange-dashed line), and the WRF-SFIRE simulation using the ICM (red-dashed line).

\subsection{L2F Smoke Simulations}

Observations from the Cessna 337 first detected smoke at 18:10 UTC, shortly after the ignition of the L2F burn plot (Figure 6). For the model evaluations carried out here, $\mathrm{CO}$ concentrations collected by the aircraft were subtracted by background $\mathrm{CO}$ concentrations to estimate smoke enhancements from the L2F burn. Background $\mathrm{CO}$ was estimated by taking the average of all $\mathrm{CO}$ measurements prior to the ignition of the L2F burn (average $=106.6 \mathrm{ppb}$ ). Furthermore, all CO enhancements that were less than $+1 \sigma$ of the background values $(10 \mathrm{ppb})$ were subsequently treated as zero (no smoke). $\mathrm{CO}$ enhancements from smoke were detected throughout the duration of $\mathrm{L} 2 \mathrm{~F}$ burn until its conclusion at 20:59 UTC. The largest CO enhancements occurred at 18:23-18:35 UTC while the aircraft was making a corkscrew transect through the center of the smoke plume. According to the corkscrew transect, the L2F smoke plume was primarily located between 400 and 1100 mASL at $18: 30$ UTC, with CO enhancements peaking at $2300 \mathrm{ppb}$ at $950 \mathrm{mASL}$ (Figure 7a). 


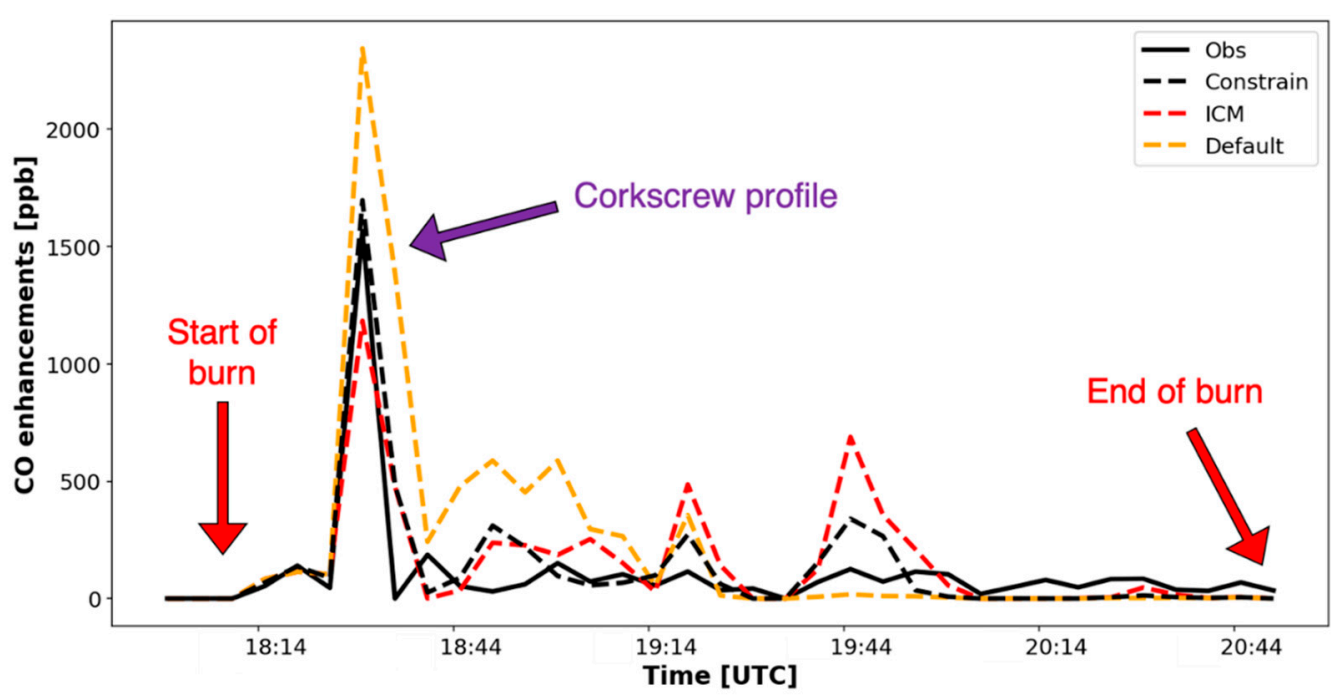

Figure 6. Modeled vs. observed CO enhancements during the L2F prescribed burn. Modeled and observed enhancements were averaged every $5 \mathrm{~min}$.

All three WRF-SFIRE simulations were able to capture the large CO enhancements associated with the corkscrew transect. The modeled $\mathrm{CO}$ enhancements within the corkscrew transect appeared to be correctly aligned with the plume centerline. These results suggest that the WRF-SFIRE simulations were able to capture the direction of the downwind smoke transport. However, capturing the vertical plume extent and vertical concentration gradients proved to be more difficult. Although the default simulation (without the ICM parametrization) produced large CO enhancements within the corkscrew transect, there were large discrepancies in regard to the magnitude and vertical position of the smoke plume. CO enhancements within the default simulation were overestimated with maximum values approaching $4000 \mathrm{ppb}$ (Figure $7 \mathrm{~b}$ ), while the observations indicated maximum concentrations of only $2000 \mathrm{ppb}$. The default simulation also overpredicted the vertical plume extent, with the plume top reaching $1800 \mathrm{mASL}$. According to the observations, the plume rise only reached an altitude of $1200 \mathrm{mASL}$. It is worth noting that the simulated plume rise for the default model run was $300 \mathrm{~m}$ higher than the stable layer observed in the radiosonde releases at 15:00 and 22:00 UTC.

The simulation with the ICM parametrization saw an improvement in both simulated CO concentrations and the vertical plume extent. Similar to the measurements, the ICM simulation produced CO enhancements that peaked at $2200 \mathrm{ppb}$ (Figure 7c). The vertical position of the modeled smoke plume was shifted upwards by $\sim 300 \mathrm{mASL}$ relative to observations, but overall, it was in better agreement with the observations relative to the default run. The constrained simulation, which was executed for reference, produced a nearly identical vertical smoke profile (not shown).

After the corkscrew transect, measured 5 min average $\mathrm{CO}$ enhancements varied between 30 and $170 \mathrm{ppb}$ as the aircraft flew in and out of the L2F smoke plume (Figure 6). The constrained and ICM configurations produced similar enhancements throughout the L2F burn. However, $5 \mathrm{~min}$ average simulated smoke concentrations were higher than the observations, with values ranging between 35-500 ppb. The default method generated CO enhancements that were $4 \times$ greater than the observed enhancements between 18:40 and 19:20 UTC. After 19:20 UTC, smoke enhancements within the default simulation dropped to $\sim 0 \mathrm{ppb}$, which occurred 50 min earlier than in the ICM and constrained simulations. The constrained and ICM runs significantly extended the period of enhanced $\mathrm{CO}$ concentrations relative to the default model simulation (Figure 6). However, modeled smoke concentrations for the constrained and ICM simulations dropped to near background levels by 20:10 UTC while smoke measurements remained elevated through 20:59 UTC. It is hypothesized that neglecting smoldering emissions within WRF-SFIRE could be responsible for the lack of smoke production after $\sim 20: 10$ UTC. This supposition is consistent with the modified combustion efficiency 
and $\mathrm{CH}_{4}$ emission factors derived from the airborne measurements, which indicated that the smoke measured in the latter portion of the sampling period was dominated by smoldering combustion [25].

The improvement of the simulated CO concentrations as a result of the ICM parameterization is also evident in the scatterplots (Figure 8). The scatterplots presented in Figure 8 are intended to show the model performance in terms of resolving the plume's spatiotemporal shape rather than the peak concentrations. Here, agreement was defined as modeled concentrations that corresponded with measurements that fell within or outside of the smoke plume. Observed smoke enhancements were identified by subtracting the raw observations from the average background concentration using the methodology described at the beginning of this section.

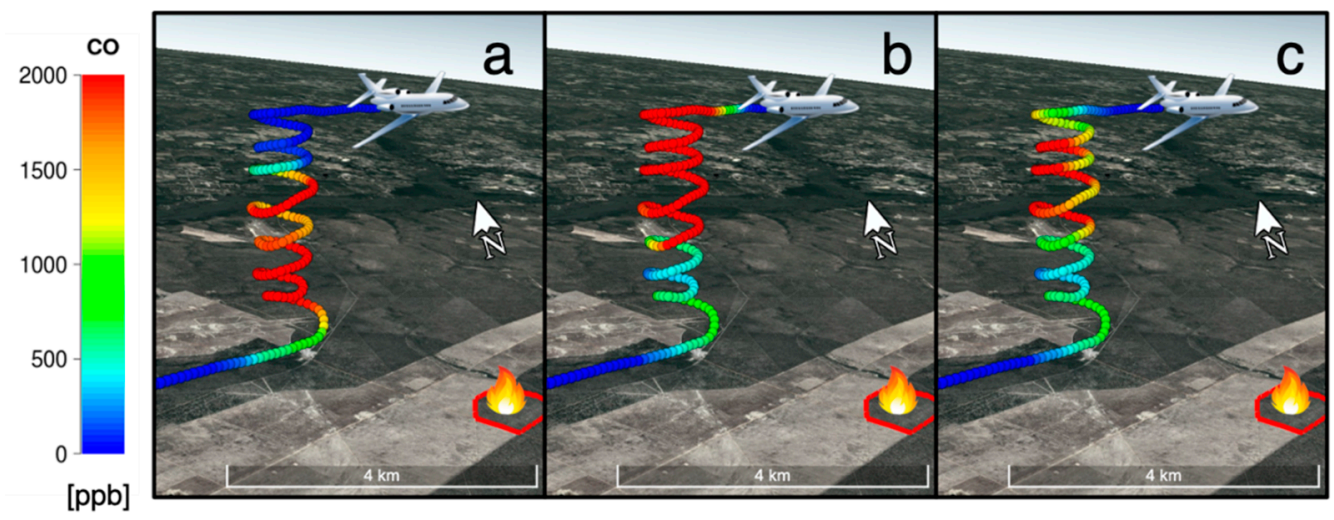

Figure 7. CO enhancements during the corkscrew transect (18:23-18:35 UTC) during the L2F prescribed burn. (a) Measured enhancements, and modeled enhancements from the (b) default and (c) ICM model simulations. The red polygon in the lower right represents the L2F burn plot.
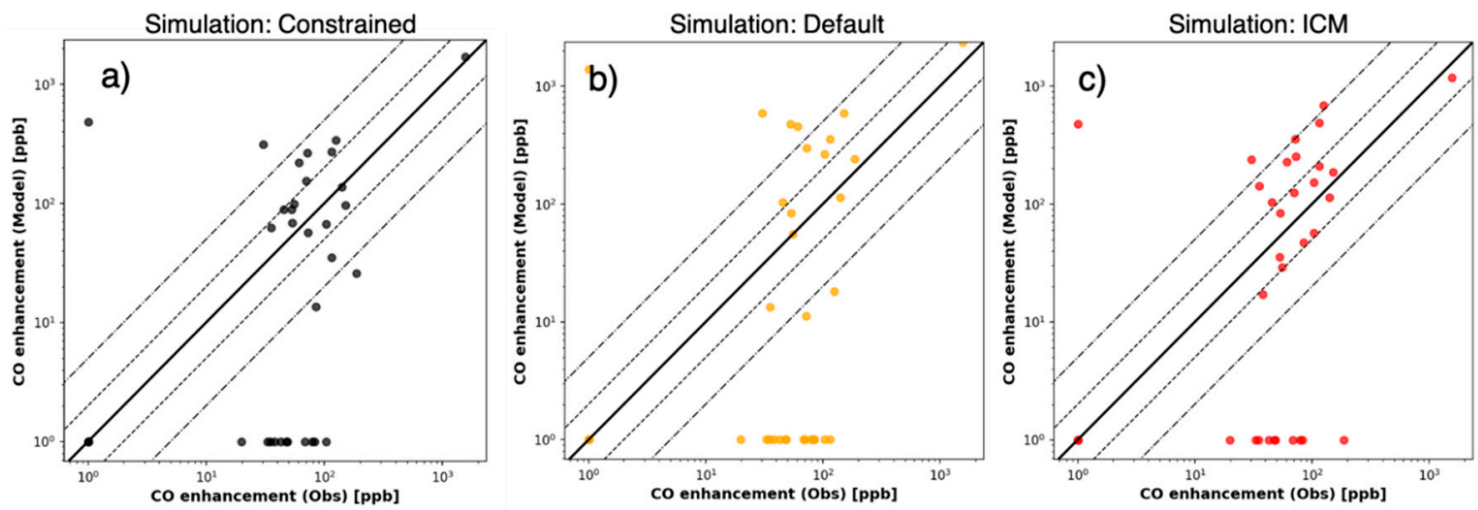

Figure 8. Scatterplots of observed vs. modeled enhancements in $\mathrm{CO}(\mathrm{ppb})$ on a logarithmic scale during the L2F prescribed burn between 18:00-20:59 UTC. The innermost dashed line represents differences within a factor of 2.5, while the outermost dashed lines mark results with differences that are within a factor of 5. (a) Measured enhancements, and modeled enhancements using the (b) default and (c) ICM configurations.

The default WRF-SFIRE simulation matched measured enhancements $43 \%$ of the time (Figure $8 \mathrm{~b}$ ). Many of the non-matched enhancements occurred towards the end of the L2F prescribed burn, due to overpredicted fire growth rates, which resulted in the fire within the default simulation arriving at the edge of the L2F burn plot 40-50 min too early. These mismatches are shown in Figure $8 \mathrm{~b}$, at the bottom of the scatter plot. In the default simulation, the fire prematurely burned out after burning through the L2F burn plot and resulted in smoke emissions that abruptly ceased. As a result, smoke production was significantly limited after 19:00 UTC. On average, the ICM and constrained runs matched observed smoke enhancements $57-63 \%$ of the time (Figure 8 a,c). The remaining $37-43 \%$ of the non-matched enhancements primarily occurred at the end of the L2F prescribed burn, when the 
ICM and constrained fires reached the edge of L2F burn plot, and emissions stopped due to the lack of a residual burning mechanism in WRF-SFIRE.

Despite the discrepancies noted above, model simulations of the L2F prescribed burn appeared to reasonably capture the width and orientation of the smoke plume as seen in Figure 9. However, there were differences, especially in terms of the horizontal plume width, which averaged around $\sim 4-\mathrm{km}$ in the ICM simulation while observations indicated a plume width of $\sim 5.5 \mathrm{~km}$. Similar plume widths were also seen in the constrained and default simulations (not shown). These differences could possibly be attributed to faster horizontal advection, which will act to stretch the smoke plume in the direction of transport.

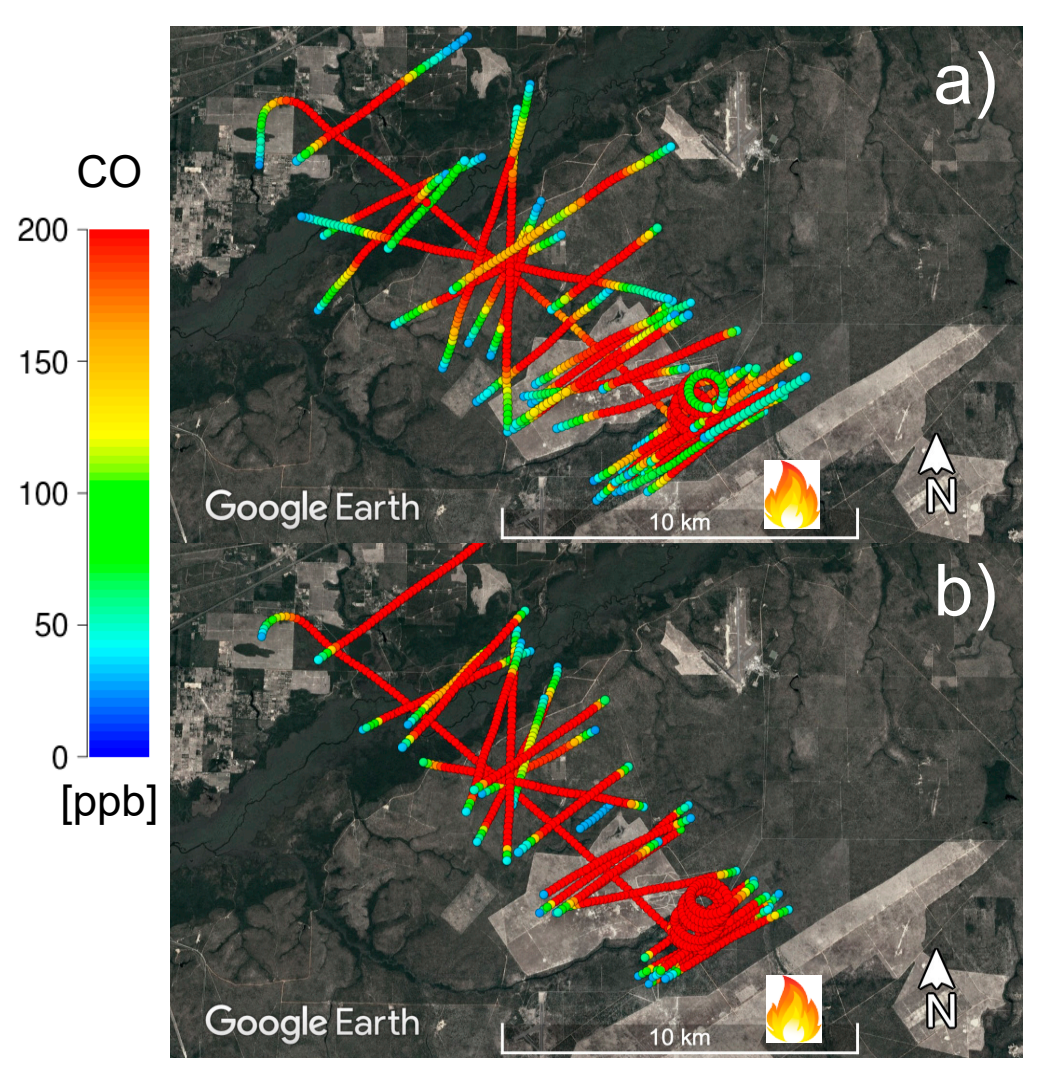

Figure 9. (a) Observed and (b) modeled smoke enhancements (ICM configuration) during the L2F prescribed burn. All enhancements at near background levels were not plotted.

In order to examine the time evolution of the vertical plume extent, vertical cross-sections of the L2F simulated plume were generated for the constrained, default and ICM simulations. Since the aircraft only flew one corkscrew profile, the constrained model configuration was treated here as the benchmark. Overall, pronounced differences were observed between each of the model configurations (constrain, default, ICM) as shown in Figure 10. The simulated plume rises for the default simulation (Figure 10d-f) exhibited a large amount of variability during the first $11 / 2$ hours of the experiment relative to constrained simulations (Figure 10a-c). Here, plume tops reached a peak altitude of 1900 mAGL (Figure 10d), before rapidly decreasing to $400 \mathrm{mAGL}$ after the first hour (Figure 10e). Presumably, the default simulation's plume rise behavior can be related back to overestimated fire growth within this simulation. Ultimately, this resulted in more intense heat fluxes (Figure 10) and a greater smoke emission rate, which translated into a shorter duration, but more intense smoke plume (Figure 10d-f). 


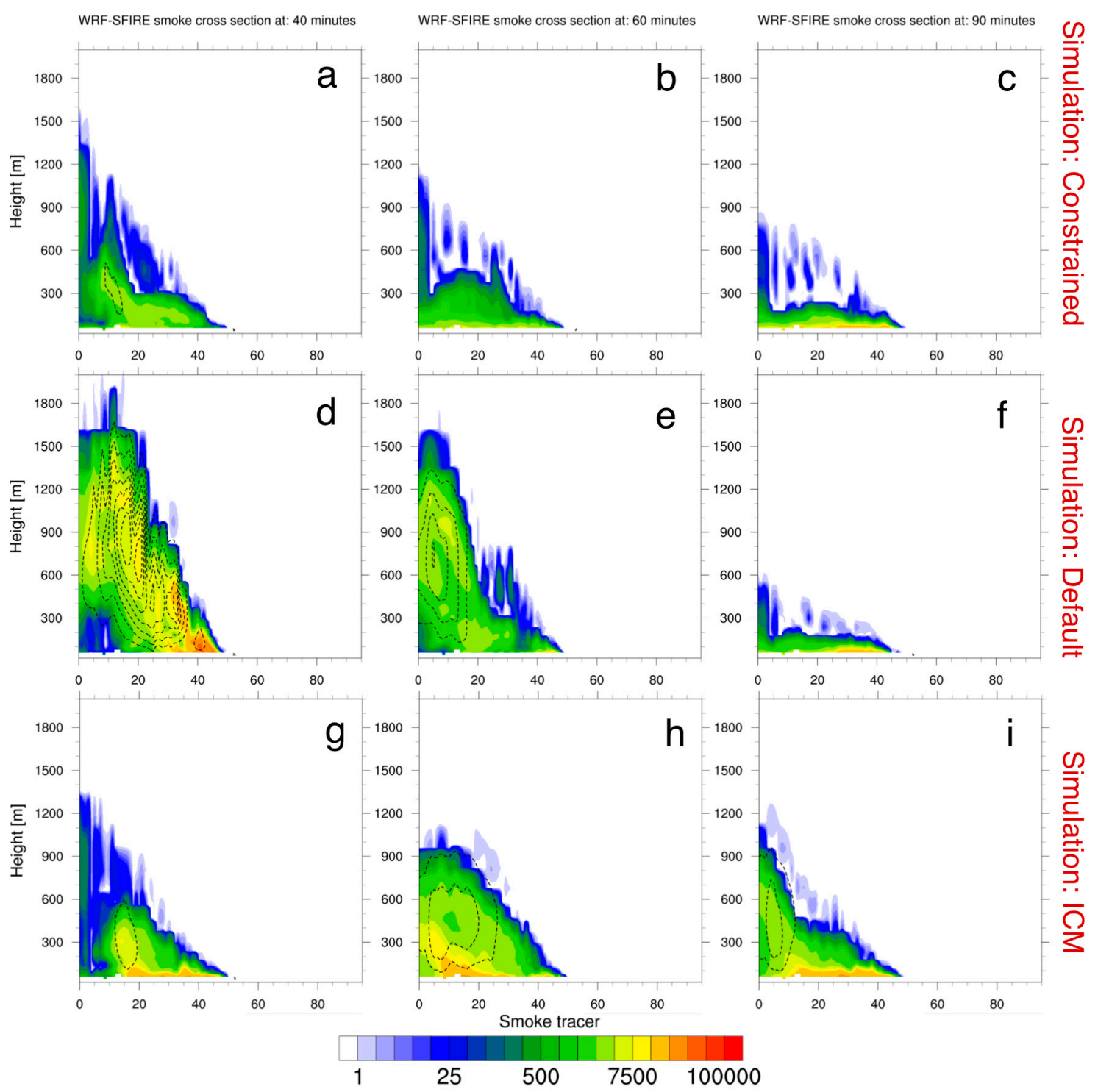

Figure 10. Vertical cross section of the L2F smoke plume along the plume centerline at 18:44 (a,d,g), 19:04 (b,e, h), and 19:34 UTC (c,f,i). The first row shows the smoke plume for the constrained simulation, while the second and third rows represents the smoke plume for the default and ICM simulations, respectively. The color-filled contour show CO enhancements (ppb), while the dashed contours represent vertical velocities every 0.5 above $0 \mathrm{~m} \mathrm{~s}^{-1}$. Minutes represent the time since the initial fire ignition at 18:04 UTC.

In contrast to the default simulation, the ICM simulation burned through the L2F burn plot at a more gradual rate (Figure 11), similar to the constrained run. Consequently, the resulting heat fluxes and emissions for the ICM simulation were steadier. The plume heights in the ICM run remained steady throughout the first $90 \mathrm{~min}$ of the L2F burn (Figure 10d-i). Here, model simulated smoke plumes reached an altitude of $1300 \mathrm{mAGL}, 40$ min into the L2F burn (18:44 UTC). Between 18:44 and 19:34 UTC, the model simulated plume tops varied between $800-1100$ mAGL, before gradually decreasing during the final hour of the experiment. This plume behavior is much closer to the constrained (Figure 10a-c) run than the default simulation (Figure 10d-f). It is worth noting that the ICM smoke concentrations later into the burn ( 19:44 UTC) appeared to be overestimated relative to the constrained run and aircraft $\mathrm{CO}$ observations (Figures 6 and 10). Here, it is hypothesized that the horizontal smoke dispersion may be under-dispersive (Figure 9), resulting in the overpredicted concentrations seen in Figure 6. 


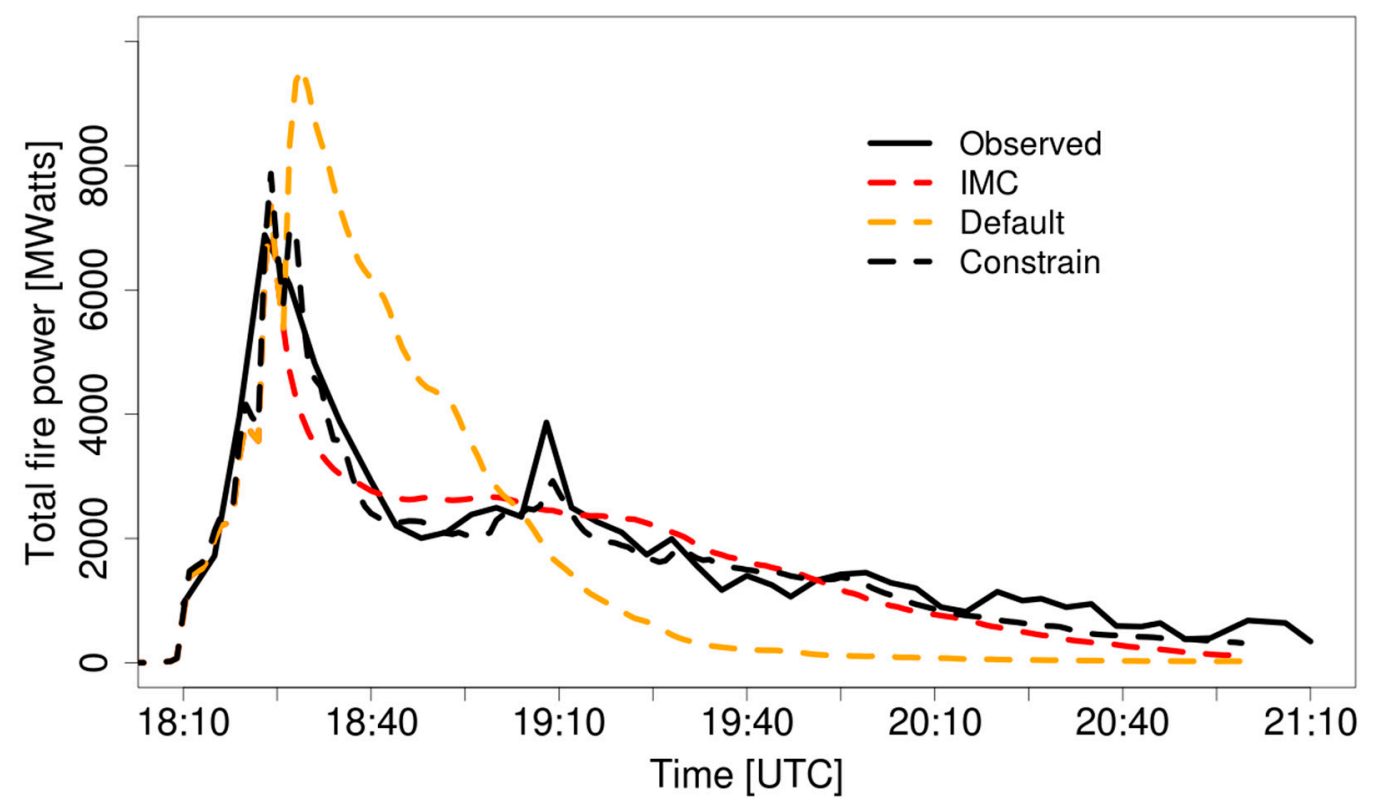

Figure 11. Observed vs. WRF-SFIRE modeled heat fluxes during the L2F prescribed burn.

\section{Conclusions}

For this study, we implemented an improved canopy model into a coupled fire-atmosphere model (WRF-SFIRE) to improve simulations of near-surface winds, fire growth rates, fire plume heights, and smoke for a prescribed forest burn. The Massman et al. [19] improved canopy model was utilized by WRF-SFIRE to produce a canopy-affected wind profile that is dependent on the vertical profile of foliage density. This implementation was then compared against default WRF-SFIRE simulations that assumed a typical logarithmic wind profile near the surface.

Wind comparisons at a tall-tower adjacent to the forest burn unit indicated that WRF-SFIRE was able to correctly reproduce ambient winds as the relative bias was less than $15 \%$ (bias $=1 \mathrm{~m} \mathrm{~s}^{-1}$ ). However, within-canopy winds for the default simulation were generally overestimated by a factor of $2\left(3.9 \mathrm{~m} \mathrm{~s}^{-1}\right)$ when compared to $3.3 \mathrm{~m}$ anemometer stations scattered throughout a forested burn plot. Wind errors were most pronounced at stations located in the middle of the forest burn plot (bias $=2.1 \mathrm{~m} \mathrm{~s}^{-1}$ ). Winds at the edge of the forest burn unit, which were adjacent to a grassy field, saw smaller errors (bias $=1.0 \mathrm{~m} \mathrm{~s}^{-1}$ ). Analyses of WRF-SFIRE simulations that implemented an improved canopy model saw reductions in model wind errors, particularly at sites located within the middle of the forest burn unit (bias $=0.4 \mathrm{~m} \mathrm{~s}^{-1}$ ).

While within-canopy winds were largely improved, underpredicted wind speeds were observed between forested and non-forested regions along the western flank of the burn unit. Here, we suspect that resolving non-local turbulence effects could be important for simulating winds along forest boundaries and will have to be investigated in the future. Furthermore, the improved canopy wind model implemented here was not dynamically coupled with the WRF atmospheric model. Results from previous work have shown that the vertical canopy structure can also affect within-canopy kinematics and temperature [21]. As a result, future work will be needed to assess to which extent dynamical coupling between the atmosphere and the canopy model can improve fire behavior and smoke model simulations. Work will also be needed to determine how the improved canopy model implemented here performs for cases of partial canopy cover [19,39].

Fire and smoke simulations proved to be sensitive to how within-canopy winds were defined. The WRF-SFIRE simulation that did not incorporate the improved canopy wind model tended to overestimate fire growth rates by a factor of 2. Subsequently, this resulted in overpredicted heat fluxes, plume tops, and downwind smoke concentrations during the first hour of the prescribed burn. These results are largely consistent with work presented in Charney et al. [22], who used 
an uncoupled fire modeling framework to simulate fire spread, heat fluxes, plume rises, and smoke concentrations. Similar to the results presented Charney et al. [22], fire growth rates, plume rises, and smoke concentrations were sensitive to how the vertical structure of the forest canopy was defined.

In the default simulation, smoke concentrations and fire growth rates were largely underestimated during the last $11 / 2$ hours of the experiment, as the fire prematurely reached the edge of the forest burn unit. The simulation that incorporated the improved canopy model was able to better reproduce fire growth rates throughout the prescribed burn. Fire heat fluxes, plume tops, and downwind smoke concentrations compared reasonably well to measurements collected during the experiments. Albeit, there is an absence of simulated smoke during the last 50 min of the experiment, when observed CO enhancements were averaging between $50-100 \mathrm{ppb}$. Previously published combustion efficiency and $\mathrm{CH}_{4}$ emission factors, derived from the airborne measurements, indicated that the smoke measured during this period was consistent with smoldering combustion [25]. These results emphasize the need for smoke modeling frameworks to account for smoldering emissions. Lastly, while fire growth rates simulated with the improved canopy wind parametrization were largely in agreement from those inferred from infrared measurements, the simulated $\mathrm{CO}$ concentrations were overestimated 1-h into the burn. It is suspected that the simplified fuel representation, which assumes uniform fuel properties, could explain some of these discrepancies. Despite the limitations presented here, this work demonstrates the importance of accounting for canopy-induced wind decelerations when simulating fire behavior and smoke with coupled fire-atmosphere models.

Author Contributions: D.V.M. and A.K.K. responsible for writing the paper and the conceptualization of the paper. D.V.M., and A.K.K. designed the experiment. D.V.M. and A.K.K. performed the experiment. D.V.M., A.K.K., J.M. and A.F. wrote and implemented canopy model code. J.M. and A.K.K. are the original architects of the WRF-SFIRE model code. S.P.U. provided and interpreted aircraft measurements. D.V.M., A.K.K. and A.F. analyzed the model output. S.K.K. responsible for obtaining funding used to support the work presented in this paper. All authors edited the paper. All authors have read and agreed to the published version of the manuscript.

Funding: This work was supported by grant NSF ICER-1664175.

Acknowledgments: The authors would like to acknowledge high-performance computing support from Cheyenne (doi:10.5065/ D6RX99HX) provided by NCAR's Computational and Information Systems Laboratory, sponsored by the National Science Foundation. The computing support from the University of Utah Center for High Performance Computing is greatly appreciated. WRF-SFIRE model code with the Massman implementation is available at: https://github.com/openwfm/wrf-fire/tree/dvm_branch.

Conflicts of Interest: The authors declare no conflict of interest.

\section{References}

1. Flannigan, M.D.; Logan, K.A.; Amiro, B.D.; Skinner, W.R.; Stocks, B.J. Future area burned in Canada. Clim. Chang. 2005, 72, 1-16. [CrossRef]

2. Spracklen, D.V.; Mickley, L.J.; Logan, J.A.; Hudman, R.C.; Yevich, R.; Flannigan, M.D.; Westerling, A.L. Impacts of climate change from 2000 to 2050 on wildfire activity and carbonaceous aerosol concentrations in the western United States. J. Geophys. Res. 2009, 114. [CrossRef]

3. Kitzberger, T.; Falk, D.A.; Westerling, A.L.; Swetnam, T.W. Direct and indirect climate controls predict heterogeneous early-mid 21st century wildfire burned area across western and boreal North America. PLoS ONE 2017, 12, e0188486. [CrossRef]

4. Westerling, A.L.; Cayan, D.R.; Swetnam, T.W. Warming and earlier spring increase western U.S. forest wildfire activity. Science 2006, 313, 940-943. [CrossRef]

5. Littell, J.S.; McKenzie, D.; Peterson, D.; Westerling, A.L. Climate and wildfire area burned in western U.S. ecoprovinces, 1961-2003. Ecol. Appl. 2009, 19, 1003-1021. [CrossRef]

6. Dennison, P.E.; Brewer, S.C.; Arnold, J.D.; Moritz, M.A. Large wildfire trends in the western United States, 1984-2011. Geophys. Res. Lett. 2014, 41, 2928-2933. [CrossRef]

7. McClure, C.D.; Jaffe, D.A. US particulate matter air quality improves except in wildfire-prone areas. Proc. Natl. Acad. Sci. USA 2018, 115, 7901-7906. [CrossRef] 
8. Liu, C.L.; Mickley, L.J.; Sulprizio, M.P.; Dominici, F.; Yue, X.; Ebisu, K.; Anderson, G.B.; Khan, R.F.; Bravo, M.A.; Bell, M.L. Particulate air pollution from wildfires in the Western US under climate change. Clim. Chang. 2016, 138, 655-666. [CrossRef]

9. Larkin, N.K.; O’Neill, S.M.; Solomon, R.; Raffuse, S.; Strand, T.; Sullivan, D.C. The BlueSky smoke modeling framework. Int. J. Wildland Fire 2009, 18, 906-920. [CrossRef]

10. Ahmadov, R.; Grell, G.; James, E.; Freitas, S.; Pereira, G.; Csiszar, I.; McKeen, S.; Pereira, G.; Freitas, S.; Straka, W.; et al. A high-resolution coupled meteorology-smoke modeling system HRRR-Smoke to simulate air quality over the CONUS domain in real time. Geophys. Res. Abstr. 2017, 19, 10841.

11. Mandel, J.; Beezley, J.D.; Kochanski, A.K. Coupled atmosphere-wildland fire modeling with WRF 3.3 and SFIRE 2011. Geosci. Model Dev. 2011, 4, 591-610. [CrossRef]

12. Kochanski, A.K.; Jenkins, M.A.; Yedinak, K.; Mandel, J.; Beezley, J.; Lamb, B. Toward an integrated system for fire, smoke and air quality simulations. Int. J. Wildland Fire 2015, 25, 534-546. [CrossRef]

13. Mandel, J.; Vejmelka, M.; Kochanski, A.K.; Farguell, A.; Haley, J.D.; Mallia, D.V.; Hilburn, K. An interactive data-driven HPC system for forecasting weather, wildland fire, and smoke. UrgentHPC 2019. [CrossRef]

14. Rothermel, R. A Mathematical Model for Predicting Fire Spread in Wildland Fuels; Intermountain Forest \& Range Experiment Station, Forest Service, US Department of Agriculture: Ogden, UT, USA, 1991; 40p.

15. Albini, F.A.; Baughman, R.G. Estimating Windspeeds for Predicting Wildland Fire Behavior; Intermountain Forest \& Range Experiment Station, Forest Service, US Department of Agriculture: Ogden, UT, USA, 1979; 12p.

16. Andrews, P.L. Current status and future needs of the BehavePlus fire modeling system. Int. J. Wildland Fire 2013, 23, 21-33. [CrossRef]

17. Andrews, P.L. Modeling Wind Adjustment Factor and Midflame Wind Speed for Rothermel's Surface Fire Spread Model; Intermountain Forest \& Range Experiment Station, Forest Service, US Department of Agriculture: Ogden, UT, USA, 2012; 39p.

18. Mueller, E.; Mell, W.; Simeoni, A. Large eddy simulation of forest canopy flow for wildland fire modeling. Can. J. For. Res. 2014, 44, 1534-1544. [CrossRef]

19. Massman, W.J.; Forthofer, J.M.; Finney, M.A. An improved canopy wind model for predicting wind adjustment factors and wildland fire behavior. Can. J. For. Res. 2017, 47, 594-603. [CrossRef]

20. Shaw, R.H.; Pereira, A.R. Aerodynamic roughness of a plant canopy: A numerical experiment. Agric. Meteorol. 1987, 26, 51-65. [CrossRef]

21. Kiefer, M.T.; Zhong, S.; Heilman, W.E.; Charney, J.J.; Bian, X. A numerical study of atmospheric perturbations induced by heat from a wildland fire: Sensitivity to vertical canopy structure and heat source strength. J. Geophys. Res. 2018, 123, 2555-2572. [CrossRef]

22. Charney, J.J.; Kiefer, M.; Zhou, S.; Heilman, W.E. Assessing forest canopy impacts on some concentrations using a coupled numerical model. Atmosphere 2019, 10, 273. [CrossRef]

23. Clements, C.B.; Lareau, N.P.; Seto, D.; Contezac, J.; Davis, B.; Teske, C.; Zajkowski, T.J.; Hudak, A.T.; Bright, B.C.; Dickinson, M.B.; et al. Fire weather conditions and fire-atmosphere interactions observed during low-intensity prescribed fires-RxCADRE 2012. Int. J. Wildland Fire 2016, 25, 90-101. [CrossRef]

24. Ottmar, R.D.; Hudak, A.T.; Prichard, S.J.; Wright, C.S.; Restaino, J.C.; Kennedy, M.C.; Vihnanek, R.E. Pre-fire and post-fire surface fuel and cover measurements collected in the southeastern United States for model evaluation and development-RxCADRE 2008, 2011 and 2012. Int. J. Wildland Fire 2016, 25, 10-24. [CrossRef]

25. Strand, T.; Gullett, B.; Urbanski, S.; O’Neill, S.; Potter, B.; Aurell, J.; Holder, A.; Larkin, N.; Moore, M.; Rorig, M. Grassland and forest understorey biomass emissions from prescribed fires in the southeastern United States-RxCADRE 2012. Int. J. Wildland Fire 2016, 25, 102-113. [CrossRef]

26. Hudak, A.T.; Dickinson, M.B.; Bright, B.C.; Kremens, R.L.; Loudermilk, E.; O'Brian, J.J.; Hornsby, B.S.; Ottmar, R.D. Measurements relating to fire radiative energy density and surface fuel consumption—RxCADRE 2011 and 2012. Int. J. Wildland Fire 2016, 25, 25-37. [CrossRef]

27. Dickinson, M.B.; Hudak, A.T.; Zajkowski, T.; Loudermilk, E.L.; Schroeder, W.; Ellison, L.; Kremens, R.L.; Holley, W.; Martinez, O.; Paxton, A.; et al. Measuring radiant emissions from entire prescribed fires with ground, airborne and satellite sensors-RxCADRE 2012. Int. J. Wildland Fire 2015, 25, 48-61. [CrossRef]

28. Kremens, R.L.; Dickinson, M.B. Estimating radiated flux density from wildland fires using the raw output of limited-bandpass detectors. Int. J. Wildland Fire 2015, 24, 461-469. [CrossRef]

29. Mallia, D.V.; Kochanski, A.K.; Urbanski, S.; Lin, J.C. Optimizing smoke and plume rise modeling approaches at local scales. Atmosphere 2018, 9, 116. [CrossRef] 
30. Urbanski, S.P. RxCADRE 2012: Airborne measurements of smoke emission and dispersion from prescribed fires. For. Serv. Res. Data Arch. 2014. [CrossRef]

31. Skamarock, W.; Klemp, J.; Dudhia, J.; Gill, D.; Barker, D.; Duda, M.; Wang, W.; Powers, J. A description of the advanced research WRF version 3. Natl. Cent. Atmos. Res. Tech. Rep. 2008. [CrossRef]

32. Saha, S.; Moorthi, S.; Wu, X.; Wang, J. The NCEP Climate Forecast System version 2. J. Clim. 2014, 27, 2185-2208. [CrossRef]

33. Hong, S.-Y.; Noh, Y.; Dudhia, J. A new vertical diffusion package with an explicit treatment of entrainment processes. Mon. Weath. Rev. 2006, 134, 2318-2341. [CrossRef]

34. Iacono, M. J.; Delamere, J.S.; Mlawer, E.J.; Shephard, M. W.; Clough, S. A.; Collins, W. D. Radiative forcing by long-lived greenhouse gases: Calculations with the AER radiative transfer models. J. Geophys. Res. 2008. [CrossRef]

35. Lin, Y.-L.; Farley, R.D.; Orville, H.D. Bulk parameterization of the snow field in a cloud model. J. Clim. Appl. Meteorol. 1983, 22, 1065-1092. [CrossRef]

36. Grell, G.A.; Devenyi, D.A. Generalized approach to parameterizing convection combining ensemble and data assimilation techniques. Geophy. Res. Lett. 2002, 29. [CrossRef]

37. Anderson, H.E. Aids to determining fuel models for estimating fire behavior. Gen. Tech. Rep. Int. 1982. [CrossRef]

38. Vejmelka, M.; Kochanski, A.K.; Mandel, J. Data assimilation of dead fuel moisture observations from remote automatic weather stations. Int. J. Wildland Fire 2015, 25, 558-568. [CrossRef]

39. Kiefer, M.T.; Heilman, W.E.; Zhong, S.; Charney, J.J.; Bian, X. A study of the influence of forest gaps on fire-atmosphere interactions. Atmos. Chem. Phys. 2016, 16, 8499-8509. [CrossRef]

(C) 2020 by the authors. Licensee MDPI, Basel, Switzerland. This article is an open access article distributed under the terms and conditions of the Creative Commons Attribution (CC BY) license (http://creativecommons.org/licenses/by/4.0/). 